\title{
Nicotine-Associated Cues Maintain Nicotine-Seeking Behavior in Rats Several Weeks after Nicotine Withdrawal: Reversal by the Cannabinoid $\left(\mathrm{CB}_{\mathrm{I}}\right)$ Receptor Antagonist, Rimonabant $(S R I 4 I 7 \mid 6)$
}

\author{
Caroline Cohen*,', Ghislaine Perrault', Guy Griebel' and Philippe Soubrié' \\ 'Sanofi-synthelabo Recherche, Bagneux, France
}

\begin{abstract}
Conditioned stimuli are important for nicotine dependence and may trigger craving and relapse after prolonged nicotine abstinence. However, little is known about the pharmacology of this process. Among the systems that have been shown to play a role in drugseeking behavior is the endocannabinoid transmission. Therefore, the present study examined the resistance to extinction of drugseeking behavior elicited by nicotine-associated environmental stimuli and the effects of the selective $\mathrm{CB}_{\text {। }}$ cannabinoid antagonist rimonabant (SRI4I7I6) on the reinforcing effects of nicotine-related stimuli. Rats were trained to self-administer nicotine $(0.03 \mathrm{mg} / \mathrm{kg} /$ injection, i.v.) under conditions in which responding was reinforced jointly by response-contingent nicotine injections and stimuli (light and tone). After self-administration acquisition, nicotine was withdrawn and lever pressing was only reinforced by contingent presentation of the audiovisual stimuli. Under such a condition, responding persisted for 3 months, following which nonpresentation of the cues produced a progressive extinction of responding. As expected, rats trained to lever-press for saline injections paired with the audiovisual stimuli did not acquire the self-administration. These findings indicate that the cues required learned association with nicotine to acquire reinforcing properties and to function as conditioned reinforcers. When administered I month following nicotine withdrawal, rimonabant ( I mg/kg, i.p.) decreased conditioned behavior. These results showing the persistence of a nicotine-conditioned behavior are congruent with the role of nicotine-related environmental stimuli in nicotine craving in abstinent smokers. Rimonabant, which has been shown previously to reduce nicotine self-administration, may be effective not only as an aid for smoking cessation but also in the maintenance of abstinence.

Neuropsychopharmacology (2005) 30, |45-155, advance online publication, 4 August 2004; doi: I0.1038/sj.npp. 130054 I
\end{abstract}

Keywords: nicotine-seeking behavior; conditioned stimuli; cannabinoid antagonist

\section{INTRODUCTION}

The high rates of relapse commonly observed during the first 6 months following smoking cessation have encouraged a search for treatment strategies that integrate prevention of relapse (Silagy et al, 1994; Covey et al, 2000). Factors such as drug-associated environmental stimuli, stress, or drug priming can trigger craving in humans and drug-seeking behavior in laboratory animals (Shaham et al, 2003; Sinha et al, 2000; Weiss et al, 2001; Brody et al, 2002). Cue-induced drug-seeking behavior can be measured in animals using second-order schedules of

\footnotetext{
*Correspondence: C Cohen, Sanofi-Synthélabo, CNS Research Department, 31 avenue Paul Vaillant-Couturier, 92220 Bagneux, France, Tel: + 33 | 453620 21, Fax: + 33 | 453620 70,

E-mail: Caroline.cohen@sanofi-synthelabo.com

Received 27 October 2003; revised 7 July 2004; accepted 9 July 2004 Online publication: 13 July 2004 at http://www.acnp.org/citations/ Npp07|30403493/default.pdf
}

drug reinforcement or extinction/reinstatement models (Markou et al, 1993). In the former, operant responding is maintained not only by the drug but also by drug-associated stimuli that serve as conditioned reinforcers (Everitt and Robbins, 2000; Schindler et al, 2002). In models of relapse, extinguished drug-seeking behavior is reinstated by presentation of stimuli previously paired with the delivery of the drug (Weiss et al, 2001; Shaham et al, 2003).

The mesolimbic dopaminergic system has been implicated in mediating drug-seeking behavior under the control of drug-conditioned cues. Presentation of cocainepaired stimuli increased dopamine release in the nucleus accumbens and amygdala in rats (Weiss et al, 2000; Ito et al, 2000). Moreover, pretreatment with dopamine receptor antagonists prevented cue-induced cocaine- and ethanolseeking behavior (Pilla et al, 1999; Ciccocioppo et al, 2001; Liu and Weiss, 2002; Vorel et al, 2002). Although the importance of conditioned cues in the acquisition of nicotine self-administration has been demonstrated 
(Goldberg et al, 1981; Caggiula et al, 2001, 2002), the mechanisms underlying nicotine-seeking behavior induced by drug-associated stimuli have not yet been investigated.

Evidence suggests that activation of endogenous cannabinoid system plays a role in mediating the motivational effects of drugs and drug-related stimuli. Pretreatment with the cannabinoid $\mathrm{CB}_{1}$ receptor antagonist rimonabant (SR141716; Rinaldi-Carmona et al, 1994) reduced nicotine, ethanol, methamphetamine, and morphine self-administration in rodents (Arnone et al, 1997; Navarro et al, 2001; Cohen et al, 2002; Vinklerova et al, 2002). Rimonabant also blocked the acquisition of conditioned place preference induced by morphine and cocaine (Chaperon et al, 1998). Although rimonabant was reported not to reduce cocaine self-administration, it prevented cocaine relapse induced by cocaine and by cocaine-associated cues in rats (De Vries et al, 2001). It also blocked heroin self-administration, and relapse precipitated by heroin priming and heroin-associated cues (De Vries et al, 2003).

The purpose of the present study was to investigate the role of cannabinoid systems in the motivational effects of nicotine-associated environmental stimuli in rats. Specifically, rats were trained to self-administer nicotine until stable drug intake was maintained. Each nicotine injection was paired with a brief tone and light cue. During subsequent sessions, nicotine injections were discontinued and responding produced the contingent presentation of the tone and light. In previous studies with nicotine and other drugs of abuse, activity in a novel environment was found to be predictive of drug self-administration acquisition (Suto et al, 2001; Piazza et al, 1989). Individual differences in vulnerability to develop self-administration were also correlated with locomotor responses to an acute injection of amphetamine (Deminiere et al, 1989). In the studies reported here, we first compared acquisition of nicotine self-administration in rats screened for their locomotor response to an acute injection of a stimulant dose of nicotine. As expected, rats with high locomotor responses to an acute injection of nicotine were more prone to selfadminister the drug than nonresponders. We therefore used this procedure in all subsequent experiments in order to avoid the surgery and training of rats that would not acquire the self-administration. In a second experiment, in order to verify that the light and tone cues did not have any reinforcing effects per se, we compared responding sustained by contingent presentation of a light/tone cue paired with nicotine injections and with saline injections. In a third experiment, after acquisition of the nicotine self-administration, nicotine was withdrawn and responding maintained by conditioned cues was assessed repeatedly for 3 months. At that time, extinction of behavior was established by withdrawing the cues. In a fourth experiment, responding was reinstated by contingent presentation of the cues, after 1 month extinction. In our last experiment, the ability of rimonabant to reduce conditioned responding was evaluated 1 month after nicotine withdrawal. As our model was slightly different from those used traditionally to measure the role of drugassociated stimuli on behavior (ie second-order schedules of drug reinforcement or extinction/reinstatement models), we verified its sensitivity to the blockade of dopaminergic transmission by testing SCH23290, a selective dopamine $\mathrm{D}_{1}$ antagonist.

\section{MATERIALS AND METHODS}

\section{Subjects}

Male Sprague-Dawley rats (IFFA CREDO, France) weighing between 200 and $220 \mathrm{~g}$ upon arrival were individually housed in a temperature-controlled facility with a 12-h reversed light/dark cycle (lights off at 0700). Animals were restricted to a daily ration of 15-20 $\mathrm{g}$ of standard laboratory food given at the end of each day and over the weekend. Animals were housed and tested in accordance with current European legislation on animal experimentation.

\section{Drugs}

Rimonabant was synthesized by Sanofi-Synthelabo, and (-)nicotine ditartrate and SCH23390 hydrochloride were obtained from Sigma, France. All doses are expressed as the free bases. Rimonabant and SCH23390 were injected as solutions or suspensions in saline containing two drops of Tween 80. Rimonabant was administered i.p. $15 \mathrm{~min}$ and SCH 23390 s.c. $15 \mathrm{~min}$ before the session, and injection volume was $2 \mathrm{ml} / \mathrm{kg}$. Nicotine was delivered i.v. and each nicotine infusion $(0.03 \mathrm{mg} / \mathrm{kg} /$ infusion $)$ was given in a volume of $0.018 \mathrm{ml}$ in $1 \mathrm{~s}$. It was administered as a solution $(\mathrm{pH} 7)$ in saline containing $0.05 \mathrm{~N} \mathrm{NaOH}(10 \%)$.

Acquisition of self-administration was performed as described previously with slight modifications (Cohen et al, 2002, 2003).

\section{Locomotor Screen}

Rats were first selected on their locomotor response to a stimulant dose of nicotine $(0.6 \mathrm{mg} / \mathrm{kg}$, s.c. $)$, a procedure that avoids the surgery and training of rats that would not acquire the self-administration. Locomotor activity was assessed in individual photocell activity cages $(39 \times 39 \times 16.5 \mathrm{~cm}$ high $)$. Rats were placed in the activity cages for a habituation period of $60 \mathrm{~min}$. They were then injected with nicotine $(0.6 \mathrm{mg} / \mathrm{kg}$, s.c. $)$ and placed in the activity cages for $30 \mathrm{~min}$. This procedure reduced basal level of activity to make the test more suitable to display nicotine-induced hyperactivity (Cohen et al, 2003). Rats that reached 100 photocell interrupts during the habituation period and an increase in locomotor activity of at least 80 photocell interrupts after nicotine injection were selected for nicotine self-administration. This criterion led to the selection of about $50 \%$ of the animals.

\section{Operant Training}

After screening of their locomotor response to nicotine, the rats were trained to press the left lever in standard two-lever operant test chambers (MED-Associates Inc., Georgia, VT) on a fixed-ratio 1 (FR1) schedule of $45 \mathrm{mg}$ food pellet reinforcement (Noyes, formula P, Lancaster, NH) in 15-min sessions. There was no light in the experimental boxes except for a red house light. Immediately after the rat was put in the chamber, the fan was turned on. Each lever press 
was reinforced by a food pellet. Tone/light cues were omitted during food reinforcement.

\section{Surgery}

After acquiring the operant behavior, animals were anesthetized with a mixture of diazepam $(3.3 \mathrm{mg} / \mathrm{kg}$, i.p.) and ketamine $(70 \mathrm{mg} / \mathrm{kg}$, i.p.) and implanted with a chronic silastic catheter in the right jugular vein. Catheter patency was checked and maintained by flushing with heparinized saline $(30 \mathrm{U} / \mathrm{ml})$ and streptokinase $(1000 \mathrm{U} / \mathrm{ml})$ before and after each self-administration session. Animals were given a minimum of 5 days to recover from surgery prior to starting self-administration sessions.

\section{Nicotine Self-Administration}

The beginning of the session was signaled by a $1 \mathrm{~s}$ cue light above the active lever, a $1 \mathrm{~s}$ tone, and the fan that was turned on automatically. Responding on the left lever (active lever) was reinforced with nicotine $(0.03 \mathrm{mg} / \mathrm{kg} / \mathrm{infusion})$ delivered in a volume of $0.018 \mathrm{ml}$ in $1 \mathrm{~s}$ (Med Associates pump, model PHM100), while responding on the right lever had no consequence. Infusions were coupled to the onset of a $20 \mathrm{~s}$ cue light above the active lever and a $1 \mathrm{~s}$ tone. During this 20-s period, lever pressing was counted but not reinforced. The infusion pump was located outside the test chamber, so that the sound produced by activation of the pump was masked by the ventilator noise and could not serve as nicotine-paired stimulus. At the beginning of nicotine selfadministration training (first three sessions), testing was automatically stopped when rats had obtained 20 nicotine infusions (to avoid nicotine overdose, ie convulsions) or when $1 \mathrm{~h}$ had elapsed. Thereafter, the session duration was set to $1 \mathrm{~h}$ and the number of nicotine infusions was not limited. Nicotine self-administration was considered as acquired when performance stabilized with at least 10 nicotine injections per session.

\section{Conditioned Responding}

Following nicotine self-administration training, rats were given daily (five times per week) $1 \mathrm{~h}$ session during which responding on the active lever produced the contingent presentation of the $1 \mathrm{~s}$ tone and $20 \mathrm{~s}$ light cue but did not activate the infusion pump. During this 20-s period, lever pressing was counted but had no consequences.

\section{Experiment 1: Acquisition of Nicotine Self-Administration in Nicotine Responders and Nonresponders}

To compare acquisition of nicotine self-administration in rats with different responses to the stimulant effect of nicotine, eight rats (nicotine responders) with an increase in activity score above 80 following nicotine administration and six rats (nicotine nonresponders) with no increase in activity score were trained to self-administer nicotine paired with the presentation of the tone and light cue for 10 sessions, as described above.
Experiment 2: Responding Maintained by Cues Paired with Nicotine or Saline Injections

In order to verify that the audiovisual cues could not maintain responding if not paired with nicotine, rats were trained to self-administer nicotine $(n=6)$ or saline $(n=10)$ paired with the presentation of the tone and light cue for 10 sessions, as described above.

\section{Experiment 3: Persistence and Extinction of Conditioned Responding}

Following nicotine self-administration, seven rats were given $1 \mathrm{~h}$ session 3-5 times per week for 3 months (55-60 sessions) during which responding on the active lever produced the contingent presentation of the nicotine paired-stimuli, in the absence of nicotine, as described above. Rats were then given 14 sessions during which lever presses had no scheduled consequences.

\section{Experiment 4: Extinction and Reinstatement of Conditioned Responding}

Following nicotine self-administration, two groups were constituted. In group $\mathrm{A}$, four rats were given $7-101 \mathrm{~h}$ sessions during which responding on the active lever produced the contingent presentation of the nicotine paired-stimuli, in the absence of nicotine. They were then given 20-30 sessions during which lever presses had no scheduled consequences. During additional two sessions, responding on the active lever produced the contingent presentation of the nicotine paired-stimuli, in the absence of nicotine (cues reinstatement). In group $B$, four rats were given 20-25 sessions during which lever presses had no scheduled consequences (no nicotine, no cues). During additional two sessions, responding on the active lever produced the contingent presentation of the nicotine paired-stimuli, in the absence of nicotine (cues reinstatement).

\section{Experiment 5: Effects of Drugs on Conditioned Responding}

Rimonabant (0.1 and $1 \mathrm{mg} / \mathrm{kg}$, i.p., $n=7)$ and SCH23390 (0.003, 0.01 and $0.03 \mathrm{mg} / \mathrm{kg}$, s.c., $n=6$ ) were tested on conditioned responding. Rimonabant was administered after 20 sessions of conditioned responding ( 1 month of nicotine withdrawal). Another group of rats was tested with SCH23390 after 30 sessions of conditioned responding. Tests were performed twice a week separated by one or two control sessions. Doses were administered in mixed order.

\section{Statistical Analysis}

Since data from self-administration experiments were not normally distributed, they were statistically analyzed using square root transformation. In experiment 1 , locomotor activity data were analyzed using two-way ANOVA with group (responders/nonresponders) and time as the two factors, followed by Dunnett's test. The number of presses on the active and inactive levers was analyzed 
independently for nicotine responders and nonresponders using two-way ANOVA with lever (active/inactive) and session as the two factors, followed by Dunnett's test. The number of reinforced responses (ie number of injections of nicotine paired with the audiovisual cues) was analyzed using two-way ANOVA with group (nicotine responders/nonresponders) and session as the two factors, followed by Dunnett's test. In experiment 2, the number of presses on the active and inactive levers was analyzed independently for nicotine self-administration and for saline self-administration using two-way ANOVA with lever (active/inactive) and session as the two factors, followed by Dunnett's test. The number of reinforced responses (ie number of injections of saline or nicotine paired with the audiovisual cues) was analyzed using twoway ANOVA with group (saline/nicotine) and session as the two factors, followed by Dunnett's test. In experiment 3, each phase was analyzed separately, that is, session 0 to sessions 55-60 (cues only) and sessions 55-60 to session 14 (no nicotine, no cues). The number of responses was analyzed using two-way ANOVA with lever (active/inactive) and session as the two factors, followed by Dunnett's test. In experiment 4, each phase was analyzed separately for each group: group A: session 0 to sessions 7-10 (cues only), sessions 7-10 to 20-25 (no nicotine, no cues), and sessions 20-25 to session 2 (cues reinstatement); group B: session 0 to sessions 20-25 (no nicotine, no cues) and sessions 20-25 to session 2 (cues reinstatement). The number of responses was analyzed using two-way ANOVA with lever (active/inactive) and session as the two factors, followed by Dunnett's test. In experiment 5, drug effects were analyzed using one-way ANOVA followed by Dunnett's test. For each drug, the control value was the mean value of performances taken from the session preceding each drug test session.

\section{RESULTS}

Experiment 1: Acquisition of Nicotine Self-Administration in Nicotine Responders and Nonresponders

Locomotor activities of nicotine responders and nonresponders were analyzed during the habituation phase and after nicotine administration. ANOVA indicated a significant group $\times$ time interaction $(\mathrm{F}(8,96)=4.58, p<0.001)$. Basal activity measured during the $1 \mathrm{~h}$ habituation period before nicotine administration was not different between nicotine responders and nonresponders. Nicotine responders, as expected, exhibited more locomotion in response to an acute injection of nicotine than nonresponders during the $20 \mathrm{~min}$ that followed the injection $(p<0.01)$. Figure 1 (top and middle panels) shows the number of responses on the active and inactive levers in nicotine responders and nonresponders. In nicotine responders, ANOVA revealed a significant lever effect $(\mathrm{F}(1,7)=110.09, p<0.01)$. Nicotine responders showed significant higher active $v s$ inactive lever pressing from session 1 to $10(p<0.01)$. Session effect and lever $\times$ session interaction were not statistically significant $(\mathrm{F}(9,63)=0.71$ and $\mathrm{F}(9,63)=1.23$, respectively). There were no statistically significant differences in either active or inactive lever pressing between day 1 and other sessions.

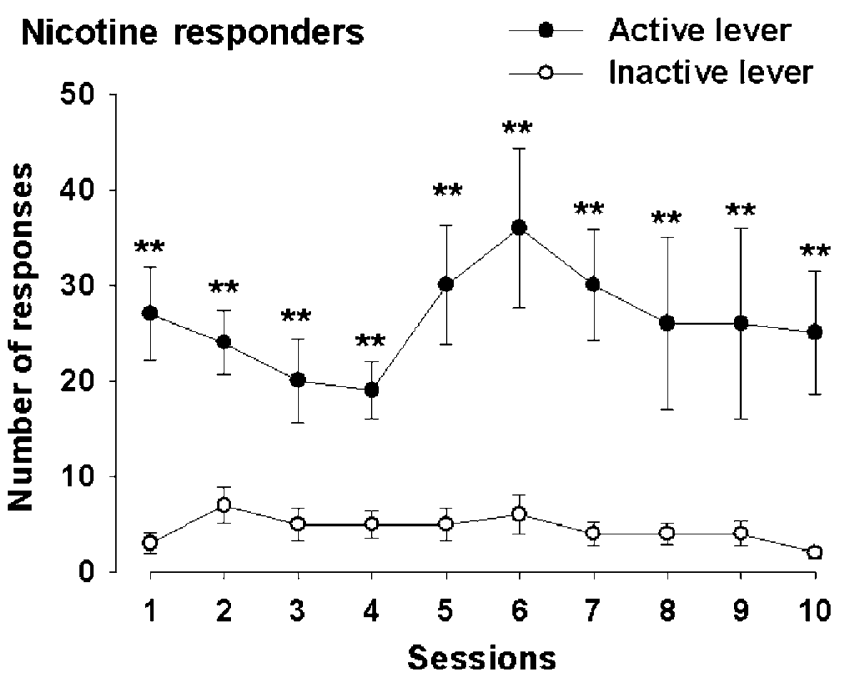

Nicotine non-responders
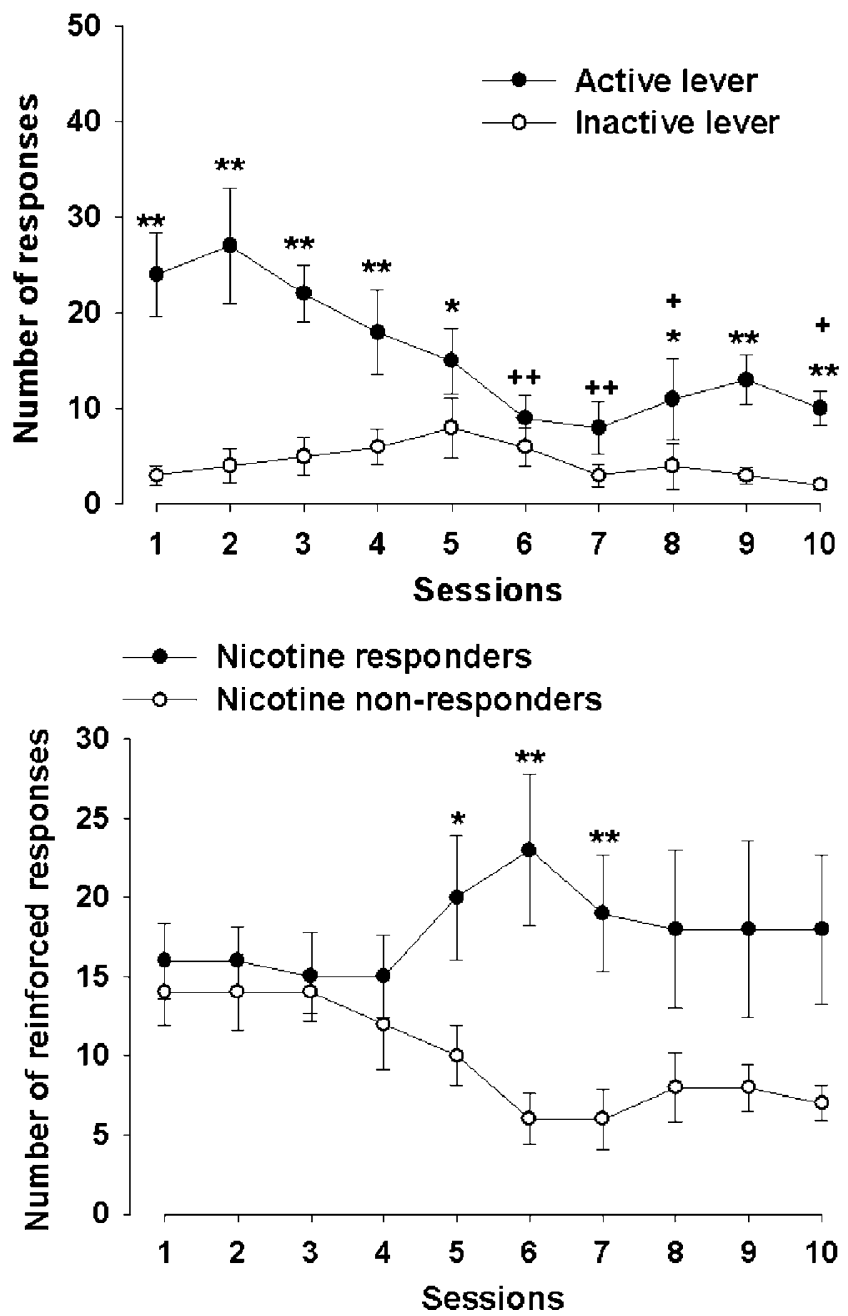

Figure I Number of responses (means \pm SEM) emitted on the active and inactive levers by nicotine responders (top panel, $n=8$ ) and nonresponders (middle panel, $n=6$ ) when given the opportunity to lever-press for nicotine paired with a light/tone cue for $10 \mathrm{I}$ h sessions. ${ }^{*} p<0.05$, ** $p<0.0$ I compared to inactive lever, $+p<0.05,++p<0.0$ I compared to session I. Bottom panel: number of reinforced responses (means $\pm S E M)$ in both groups. $* p<0.05, * * p<0.01$ compared to nicotine nonresponders. 
In nicotine nonresponders, ANOVA revealed a significant lever effect $(\mathrm{F}(1,5)=321.46, p<0.01)$ and lever $\times$ session interaction $\mathrm{F}(9,45)=5.60, p<0.01)$. The session effect was not significant $(\mathrm{F}(9,45)=1.87$, NS). In nicotine nonresponders, the number of responses on the active lever decreased progressively $(\mathrm{F}(9,95)=4.99, p<0.01)$. Active lever pressing was significantly reduced during sessions $6-8$ and 10 as compared to session 1. Nicotine nonresponders showed significant higher active $v s$ inactive lever pressing on sessions $1-5$ and $8-10$. When comparing the number of nicotine injections obtained by nicotine responders and nonresponders, ANOVA revealed a significant group effect $(\mathrm{F}(1,12)=6.40, p<0.05)$ and group $\times$ session interaction $(\mathrm{F}(9,108)=2.0, \quad p<0.05)$. Nicotine responders obtained more nicotine injections than nonresponders on sessions 5-7 (Figure 1, bottom panel). Differences were close to significance on sessions 8-10 $(p<0.07)$. Six nicotine responders out of eight reached the self-administration criterion at session 10, whereas one out of six reached it in the nonresponder group. Given the poor performance of nonresponders, they were not included in other experiments.

\section{Experiment 2: Responding Maintained by Cues Paired} with Nicotine or Saline Injections

Figure 2 (top and middle panels) shows the number of responses on the active and inactive levers in rats when given the opportunity to lever-press for nicotine + cues or saline + cues. In rats responding for nicotine, ANOVA revealed a significant effect of active $v s$ inactive lever $(\mathrm{F}(1,10)=44.8, p<0.01)$. Session effect and lever $\times$ session interaction were not statistically significant $(F(9,90)=0.63$ and $\mathrm{F}(9,90)=1.32$, respectively). Rats showed significant higher active $v s$ inactive lever pressing from day 1 to 10 . There were no statistically significant differences in either active or inactive lever pressing between day 1 and other sessions. In rats responding for saline, ANOVA revealed a significant effect of lever $(\mathrm{F}(1,9)=51.6, p<0.01)$, session $(\mathrm{F}(9,81)=3.59, \quad p<0.01)$, and lever $\times$ session interaction $(\mathrm{F}(9,81)=5.11, p<0.01)$. Rats showed significant higher active $v s$ inactive lever pressing from session 1 to 9 . The number of responses on the active lever decreased progressively $(\mathrm{F}(9,171)=6.19, p<0.01)$. Active lever pressing was significantly reduced during sessions 2 and $6-10$ as compared to session 1 . When comparing the number of nicotine $v s$ saline injections obtained by rats, ANOVA revealed a significant group effect $(\mathrm{F}(1,19)=13.0, p<0.01)$ and group $\times$ session interaction $(\mathrm{F}(9,171)=2.54, p<0.05)$. Rats self-administered more nicotine than saline injections on all testing days except on days 1, 3, and 6 (Figure 2, bottom panel). Further analysis indicated a significant session effect for the saline group $(F(9,171)=2.88$, $p<0.01)$. Differences in the number of saline injections were significant between session 1 and sessions 7, 9, and 10 . When given access to nicotine, 10 out of 11 rats reached the self-administration criterion at session 10 , whereas when given access to saline, three out of 10 erratically reached it. Given the poor performance of rats under the saline + cue condition, they were not included in other experiments.

\section{Nicotine + cues self-administration}

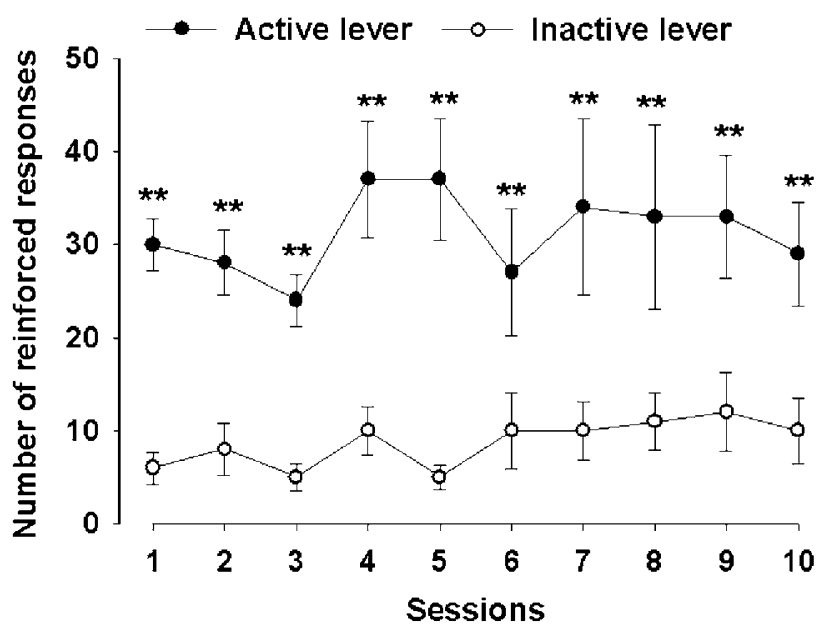

Saline + cues self-administration
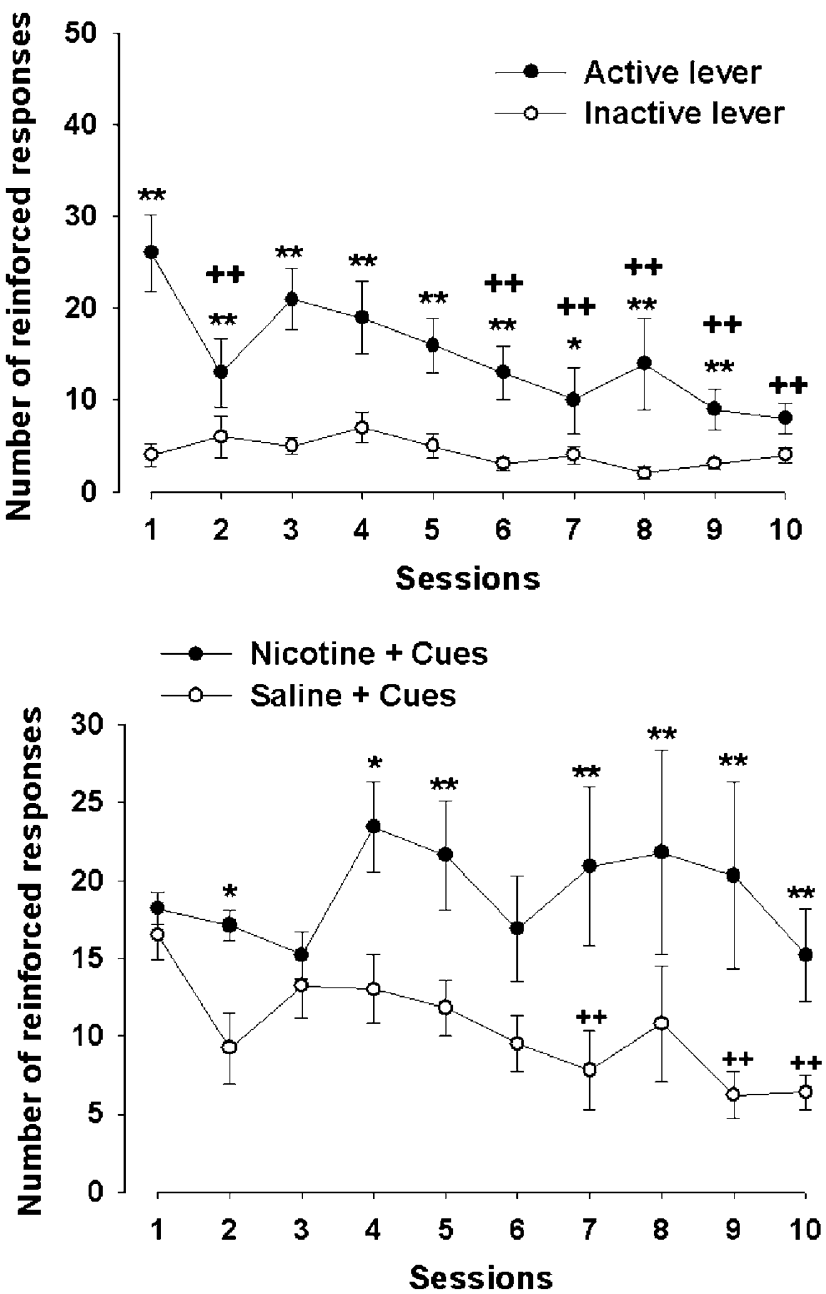

Figure 2 Number of responses (means \pm SEM) emitted on the active and inactive levers by rats when given the opportunity to lever-press for nicotine (top panel, $n=6$ ) or for saline (middle panel, $n=10$ ) injections paired with a light/tone cue for $10 \mathrm{I} h$ sessions. $* p<0.05$, ** $p<0.01$ compared to inactive lever, $++p<0.01$ compared to session I. Bottom panel: number of reinforced responses (means $\pm S E M$ ) in both conditions. ${ }^{*} p<0.05, * * * 0.01$ compared to saline, $++p<0.05$ compared to session I. 


\section{Experiment 3: Persistence and Extinction of Conditioned Responding}

Figure 3 shows responses on the active (reinforced lever) and inactive lever during the last day of nicotine selfadministration (cues plus nicotine injections), on sessions $1,7,14,21,28,35,42,49$, and 55-60 following nicotine withdrawal (cues only) and on sessions 1-14 following cues withdrawal (no nicotine, no cues). For the first phase (cues only), ANOVA indicated significant lever effect $(\mathrm{F}(1,6)=45.73, \quad p<0.01)$ and lever $\times$ day interaction $(\mathrm{F}(9,54)=2.27, p<0.05)$. Day effect was not statistically significant $(F(9,54)=1.03$, NS). When nicotine was withdrawn, the number of responses on the active lever with contingent presentation of the cues was maintained for up to 55-60 sessions (ie about 3 months at the rate of 3-5 sessions per week) at the same rate as during nicotine selfadministration. For the second phase (no nicotine, no cues), ANOVA indicated significant lever effect $(\mathrm{F}(1,6)=64.88$, $p<0.01)$, day effect $(\mathrm{F}(14,84)=5.62, p<0.01)$, and lever $\times$ day interaction $(\mathrm{F}(14,84)=3.42, p<0.01)$. When the cues were withdrawn, responding on the active lever was progressively extinguished.

\section{Experiment 4: Extinction and Reinstatement of Conditioned Responding}

Figure 4 (top panel) shows responses for group A on the active (reinforced lever) and inactive lever during the last day of nicotine self-administration (cues plus nicotine injections), on sessions 1-6 and on the last session (ie 7 or 10) following nicotine withdrawal (cues only), on sessions 1-14 and on the last session (ie 20 or 25) following cues withdrawal (no nicotine, no cues), and on sessions 1 and 2 following cues reinstatement. For the first phase (cues only), ANOVA indicated significant lever effect $(F(1,3)=24.18$, $p<0.05)$. Session effect $(F(7,21)=0.58, \mathrm{NS})$ and lever $\times$ session interaction $(F(7,21)=0.85$, NS) were statistically not significant. When nicotine was withdrawn, the number of responses on the active lever with contingent presentation of the cues was maintained at the same rate as during nicotine self-administration. For the second phase (no nicotine, no cues), ANOVA indicated significant lever effect $(\mathrm{F}(1,3)=22.16, p<0.05)$ and session effect $(\mathrm{F}(15,45)=$ 4.37, $p<0.01)$. Lever $\times$ session interaction was not statistically significant $(\mathrm{F}(15,45)=1.54$, NS). When the cues were withdrawn, responding on the active lever was progressively extinguished. For the third phase (cues reinstatement), ANOVA indicated significant lever effect $(\mathrm{F}(1,3)=40.93$, $p<0.01)$, session effect $(\mathrm{F}(2,6)=10.76, p<0.05)$, and lever $\times$ session interaction $(\mathrm{F}(2,6)=15.61, p<0.01)$. When the cues were reintroduced, responding increased and reached the same response rates as before extinction.

Figure 4 (bottom panel) shows responses for group B on the active (reinforced lever) and inactive lever during the last day of nicotine self-administration (cues plus nicotine injections), on sessions 1-14 and on the last session (ie 20 or 25) following nicotine and cues withdrawal (no nicotine, no cues), and on sessions 1 and 2 following cues reinstatement. For the first phase (no nicotine, no cues), ANOVA indicated significant lever effect $(\mathrm{F}(1,3)=12.03$, $p<0.05)$, session effect $(F(15,45)=3.71, p<0.01)$, and lever $\times$ session interaction $(F(15,45)=3.17, p<0.01)$. When both nicotine and cues were withdrawn, responding on the active lever was progressively extinguished. For the second phase (cues reinstatement), ANOVA indicated significant session effect $(\mathrm{F}(2,6)=6.01, \quad p<0.05)$. Lever effect $(\mathrm{F}(1,3)=5.04, \quad \mathrm{NS})$ and lever $\times$ session interaction $(\mathrm{F}(2,6)=1.69$, NS) were not significant. When the cues were reintroduced, responding increased and reached the same response rates as before extinction, however with high individual variability.

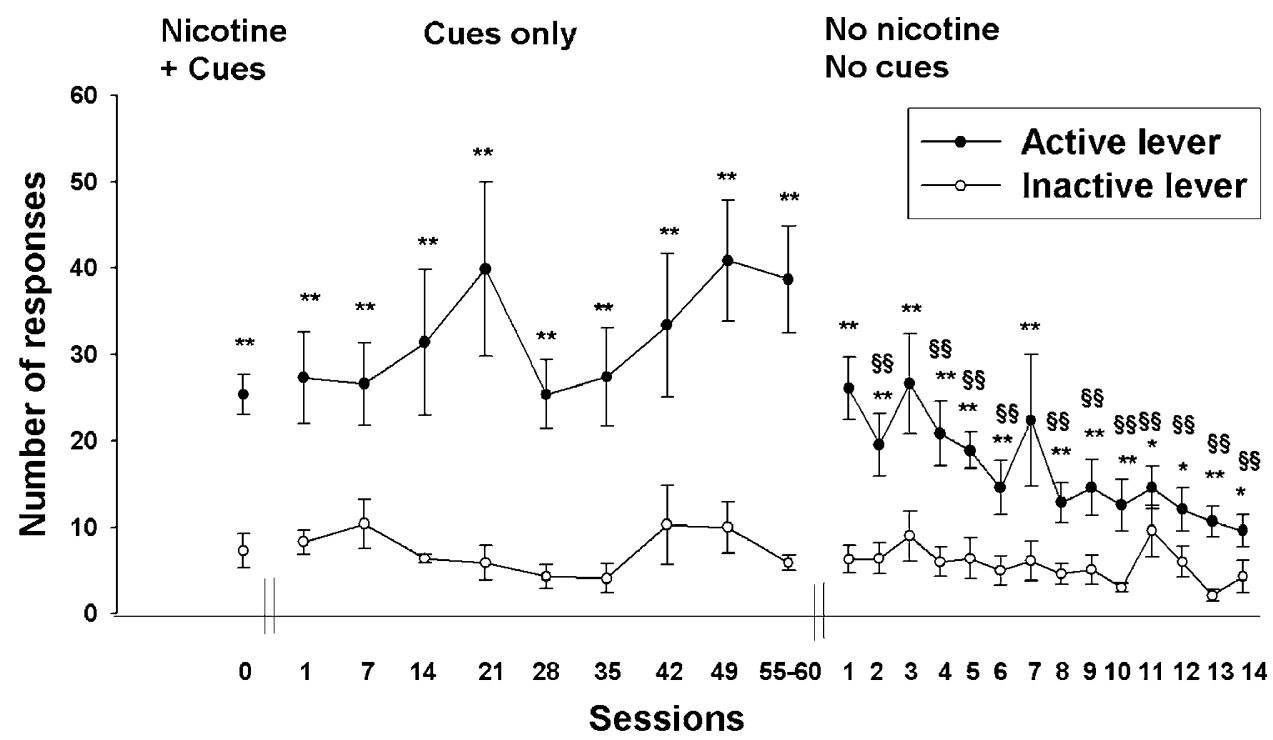

Figure 3 Number of presses on the active and inactive levers (means $\pm S E M$, based on seven rats) during the last session of nicotine self-administration (nicotine + cues), at I, 7, I4, 21, 28, 35, 42, 49, and 55-60 sessions (ie I, I 0, 20, 30, 45, 55, 65, 75, 90-95 days) following nicotine withdrawal (cues only) and at $I-14$ sessions (ie I-20 days) following cue withdrawal (no nicotine, no cues). $* p<0.05$, $* * x<0.0$ I compared to inactive lever, $\$ \$ p<0.01$ compared to sessions 55-60. 


\section{Group A}

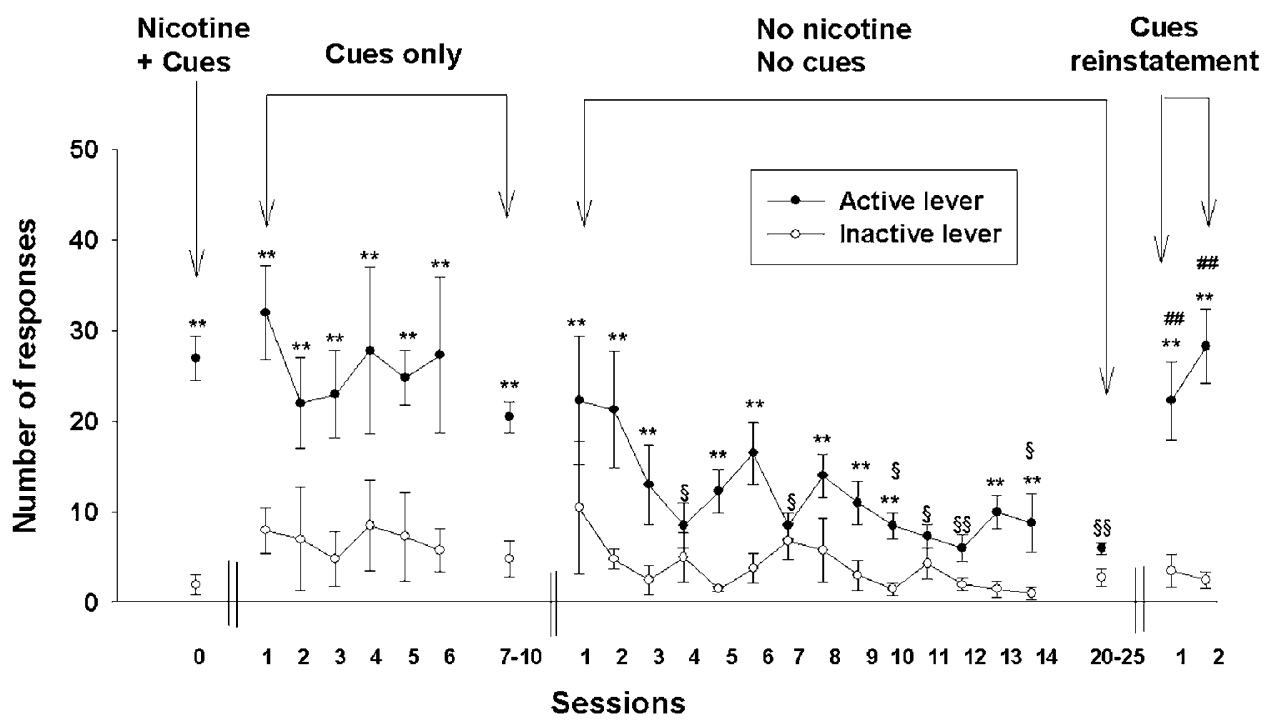

Group B

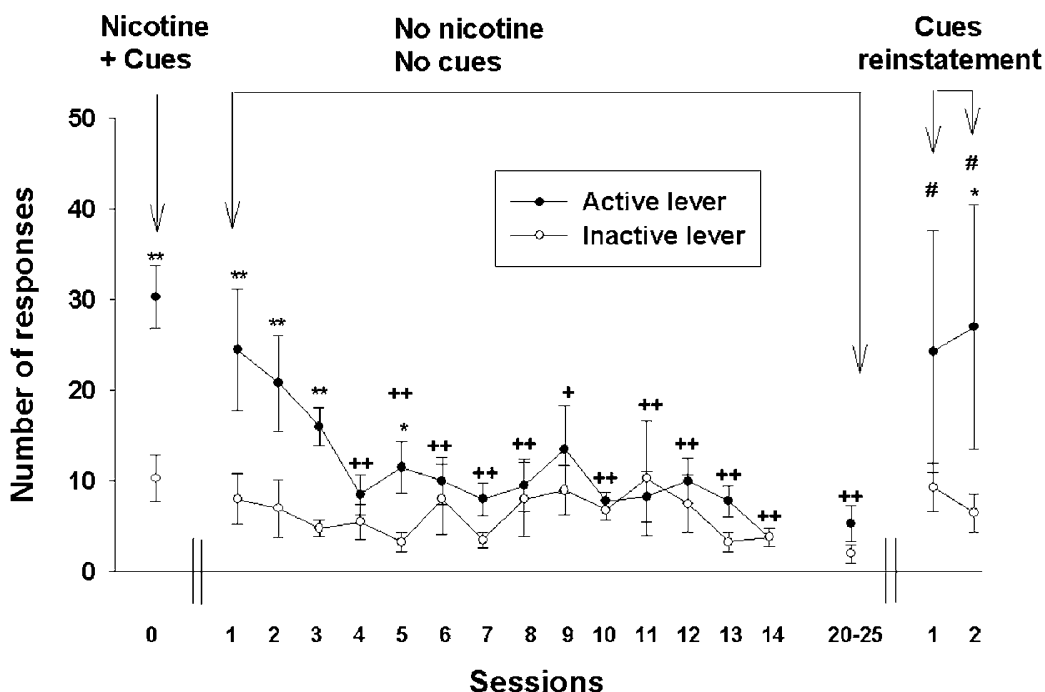

Figure 4 Top panel (group A): number of presses on the active and inactive levers (means \pm SEM, based on four rats) during the last session of nicotine self-administration (nicotine + cues), on sessions I-6 and on the last session (ie 7 or 10) following nicotine withdrawal (cues only), on sessions I-I4 and on the last session (ie 20 or 25) following cues withdrawal (no nicotine, no cues), and on sessions I and 2 following cues reinstatement. $* * *<<0.0$ I compared to inactive lever, $\$ p<0.05, \$ \$ p<0.01$ compared to the last 'cues-only' session, \#\#p<0.01 compared to the last 'no nicotine, no cues' session. Bottom panel (group B): number of presses on the active and inactive levers (means \pm SEM, based on four rats) during the last session of nicotine self-administration (nicotine + cues), on sessions $|-| 4$ and on the last session (ie 20 or 25) following cues withdrawal (no nicotine, no cues), and on sessions $\mid$ and 2 following cues reinstatement. $* p<0.05$, $* * 0.01$ compared to inactive lever, $+p<0.05,++p<0.01$ compared to the last 'nicotine + cues' session, $\# p<0.05$ compared to the last 'no nicotine, no cues' session.

\section{Experiment 5: Effects of Drug Treatment on Conditioned Responding}

As shown in Figure 5, rimonabant, at a dose of $1 \mathrm{mg} / \mathrm{kg}$ i.p., decreased the number of responses on the active lever $(\mathrm{F}(2,12)=3.97, p<0.05)$ and had no significant effects on the number of presses on the inactive lever $(\mathrm{F}(2,12)=2.61$, NS). As shown in Figure 6, SCH23390 at 0.01 and $0.03 \mathrm{mg} / \mathrm{kg}$ reduced the number of presses on the active lever $(\mathrm{F}(3,15)=18.48, p<0.01)$ and had no significant effects on the number of presses on the inactive lever $(\mathrm{F}(3,15)=1.37, \mathrm{NS})$.

\section{DISCUSSION}

The present results indicate, in agreement with previous report with amphetamine (Deminiere et al, 1989), that rats with high locomotor responses to an acute injection of nicotine were more prone to self-administer the drug than nonresponders. Even though a small number of animals were included in the experiment, differences in the level of performance reached by nicotine responders and nonresponders, that is, number of nicotine infusions and active $v s$ inactive lever pressing, were statistically significant. This procedure was therefore used in all subsequent experiments 
Nicotine-associated cues
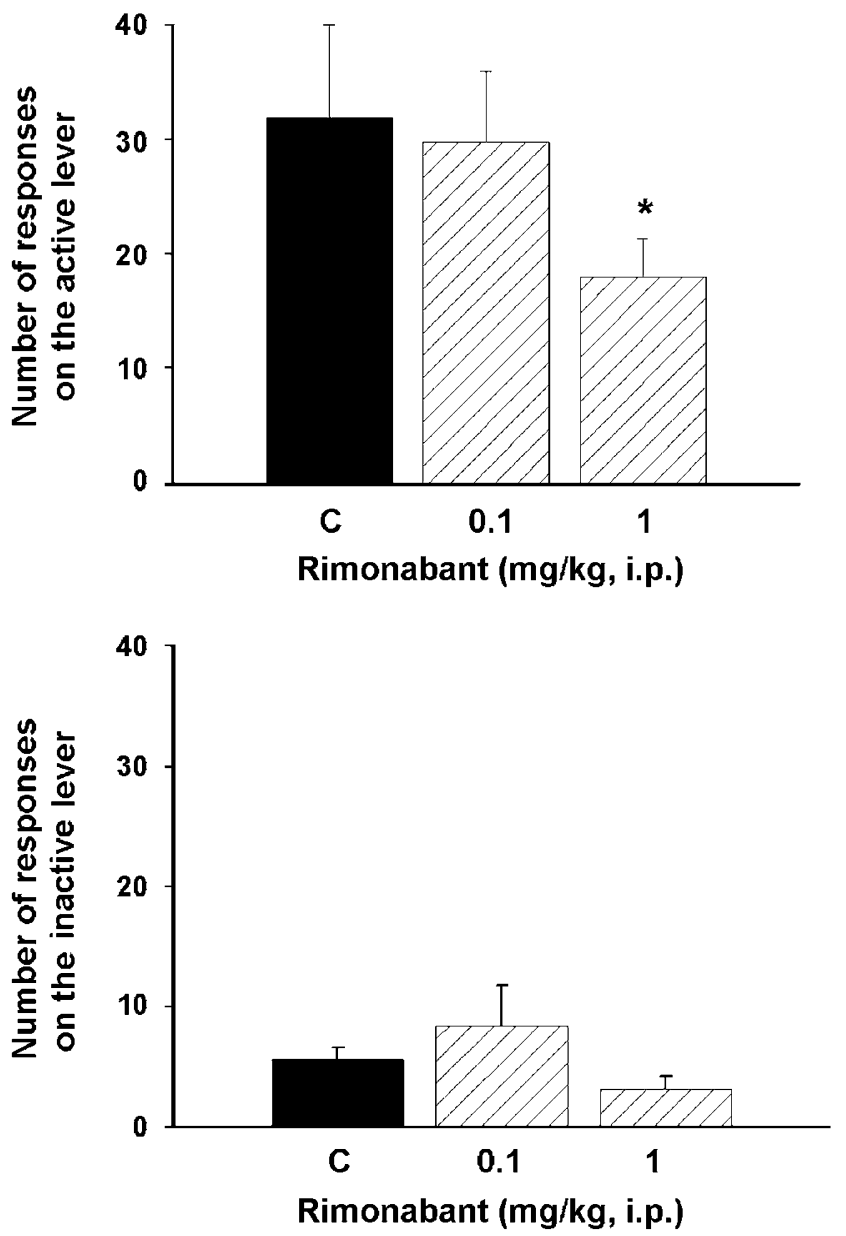

Figure 5 Effects of rimonabant on the number of presses (means \pm SEM) on the active and inactive levers. Rimonabant was administered after 20 sessions of conditioned responding. Session duration was I h. *p $<0.05$ compared to control values.

in order to avoid the surgery and training of rats that would not acquire the self-administration. Further, this is a clinically relevant procedure that focused on subjects susceptible to develop a nicotine self-administration behavior.

The importance of nicotine-associated cues in extinction of nicotine-seeking behavior was clearly demonstrated by the present finding that nicotine-associated cues can sustain responding, even after several months of nicotine abstinence. In contrast, cues paired with saline delivery did not acquire motivational effects. Previous studies have shown that contingent presentations of cocaine- (but not heroin-) associated stimuli retarded extinction of behavior under second-order schedules of reinforcement (Arroyo et al, 1998; Alderson et al, 2000) and that cocaine- and ethanolassociated stimuli reinstated responding several weeks after self-administration behavior has been extinguished (Ciccocioppo et al, 2001; Liu and Weiss, 2002). Here we report that conditioned stimuli can maintain responding after extensive testing in the absence of the drug. Conditioned responding was still observed following 60 testing sessions (ie 3 months) without nicotine reinforcement. Removal of the

\section{Nicotine-associated cues}
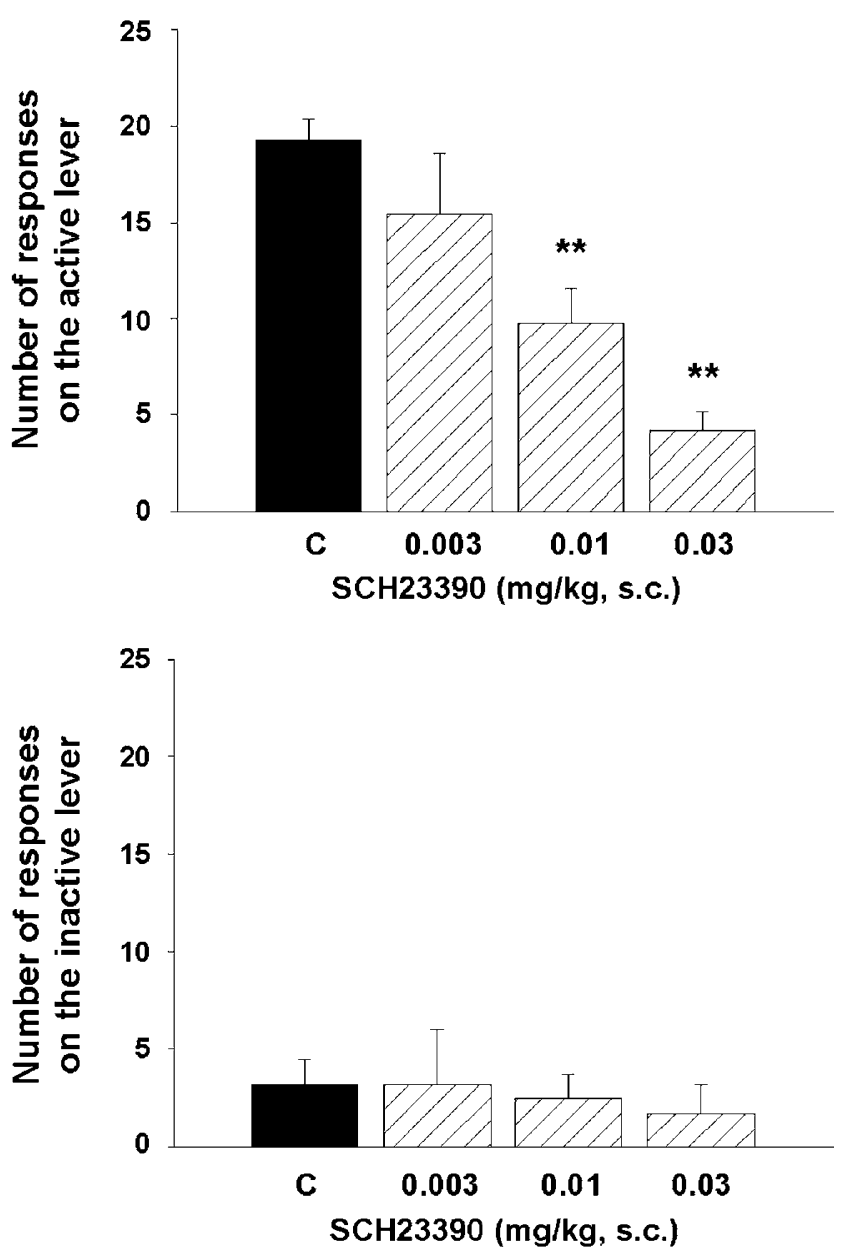

Figure 6 Effects of SCH23390 on the number of presses (means \pm SEM) on the active and inactive levers. SCH23390 was administered after 30 sessions of conditioned responding. Session duration was I h. $* * * 0.0$ I compared to control values.

cues following 3 months of nicotine withdrawal produced a progressive decrease of responding. In addition, it was shown in a separate experiment that responding could be reinstated by contingent presentation of the cues, after 1 month extinction (ie testing with no nicotine and no cues reinforcement). Cues-induced reinstatement of operant responding was more consistent across animals when an intermediate period of conditioned responding was introduced in between nicotine + cues self-administration and extinction, suggesting that this intermediate testing period has consolidated the appetitive value of the cues. Environmental cues are particularly important for nicotine selfadministration acquisition (Goldberg et al, 1981; Caggiula et al, 2001). Adding cues to nicotine has been shown to increase the average number of infusions and the proportion of rats that acquired the self-administration (Caggiula et al, 2002).

It is possible that nicotine through its action on memory processes may particularly promote associative mechanisms (Olausson et al, 2003). Nicotine facilitates several important aspects of cognitive processes including attention, learning, and memory in several animal models (Rezvani and Levin, 
2001). The hippocampus, frontal cortex, and midbrain dopamine nuclei have been found to be important sites of action for nicotinic involvement in memory function. For instance, nicotine might improve ability to focus attentional resources on task-relevant stimuli through an action on cortical cholinergic neurotransmission, resulting in increased salience of target stimuli. Moreover, our rat selection based on a pharmacological susceptibility (ie sensitivity to the stimulant effects of nicotine) might have helped screening rats particularly capable to associate discrete stimuli to the delivery of nicotine and/or to promote the acquisition of motivational properties by nicotine-associated stimuli. It has not been possible to test conditioned behavior in nicotine nonresponder rats as they failed to acquire nicotine selfadministration.

Recent evidence from studies of reinstatement of drug-seeking behavior after termination of drug taking demonstrated that the interval elapsed since a drug was last self-administered affected drug seeking. Responding elicited by drug-associated cues increased over 2 months of cocaine withdrawal (Grimm et al, 2001). Similarly, rats' sensitivity to stress-induced reinstatement was higher following 6, 12, and 25 days of heroin withdrawal than after 1 day of withdrawal (Shalev et al, 2001). In the present study, conditioned responding did not increase linearly over time. A larger number of rats would be necessary to pinpoint a withdrawal period effect. In addition, in our experiments, the same rats were repeatedly tested for 60 sessions, whereas in the cocaine and heroin withdrawal studies, different group of animals were used for each time point.

We have shown previously that the $\mathrm{CB}_{1}$ antagonist, rimonabant $(0.3 \mathrm{mg} / \mathrm{kg}$, i.p. $)$, reduced nicotine self-administration in rats (Cohen et al, 2002). Here, we report that rimonabant ( $1 \mathrm{mg} / \mathrm{kg}$, i.p.) reduced responding maintained by nicotine-associated cues, in the absence of nicotine. The lack of effects of rimonabant on the inactive lever presses is of limited use in providing a conclusive control for motor artifacts because of the low response rates. However, at this dose, the drug did not produce any gross behavioral effects (Arnone et al, 1997), suggesting that the reduction of conditioned responding did not result from nonspecific (motor) deleterious effects. In addition, it has been reported that rimonabant did not affect operant responding for food (Navarro et al, 2001), or a $10 \%$ sucrose solution (De Vries et al, 2001) or cocaine injections (Fattore et al, 1999), suggesting that it did not affect the reward system per se.

In a previous study, we have identified mesolimbic dopaminergic transmission as a possible neurochemical substrate of rimonabant-induced reduction of nicotine selfadministration (Cohen et al, 2002). Indeed, rimonabant reduced the dopamine-releasing effects of nicotine as assessed by brain microdialysis and drug discrimination. A large body of evidence has shown that dopaminergic transmission plays a role in conditioned responses associated with drugs (Everitt et al, 2001; Shaham et al, 2003). As expected, the $\mathrm{D}_{1}$ dopamine antagonist SCH23390 (0.01 and $0.03 \mathrm{mg} / \mathrm{kg}$ ) was found to reduce responding for conditioned cues. At the lowest dose, the drug has been shown to reduce locomotor activity induced by nicotine or by nicotine-associated cues without impairing motor performance (O’Neill et al, 1991; Bevins et al, 2001). Functional imaging studies in nicotine- and cocainedependent individuals have shown that exposure to drugrelated stimuli elicits craving and activates brain regions associated with arousal, compulsive repetitive behaviors, sensory integration, and episodic memory (Brody et al, 2002; Childress et al, 1999). Prefrontal cortical and limbic regions are also activated by nicotine- and cocaineassociated cues in rats, as measured by increased gene expression and dopamine release (Schroeder et al, 2001; Ito et al, 2000; Ciccocioppo et al, 2001; Phillips et al, 2003). Lesions of the basolateral amygdala or the prefrontal cortex disrupted responding maintained by cocaine-associated cues (McLaughlin and See, 2003). Intrabasolateral amygdala injections of SCH23390 blocked cue-induced reinstatement of cocaine seeking (See et al, 2001). Hippocampal, amygdala, and prefrontal cortex mechanisms may influence cocaine seeking through their convergent projections to the nucleus accumbens (Everitt et al, 2001). $\mathrm{CB}_{1}$ receptors are densely expressed in the amygdala, cortex, and hippocampus (Mailleux and Vanderhaeghen, 1992), and cannabinoid agonists have been shown to inhibit excitatory inputs from these brain regions to neurons in the nucleus accumbens shell (Pistis et al, 2002), suggesting several sites of action for rimonabant in drug addiction phenomena. The transition from voluntary drug seeking to a compulsive habit may also depend on the disruption of executive control provided by descending influences on striatal mechanisms from the prefrontal cortex. Persistent changes in striatal function during the progression of addiction might be brought about by mechanisms of long-lasting synaptic plasticity (Gerdeman et al, 2003). Recent studies have revealed that in the striatum, such mechanisms are strongly regulated by dopamine signaling and are also influenced by other signaling systems such as the endocannabinoid system. It is possible that nicotine-associated cues stimulate dopamine neurotransmission in specific brain regions as it was shown for cocaine-associated cues (Ito et al, 2000, 2002; Phillips et al, 2003). Rimonabant might prevent such activation and/ or its effects on postsynaptic transmission (Cohen et al, 2002).

In conclusion, the present study demonstrated the persistence of a conditioned behavior maintained by nicotine-related cues and extends existing evidence for a role of cannabinoid transmission in conditioned responses associated with drugs. We have shown previously that rimonabant reduced the dopamine-releasing and motivational effects of nicotine. We report here that rimonabant also reduced responding maintained by nicotine-conditioned cues, even after several months of nicotine abstinence, suggesting that the compound may be effective not only as an aid for smoking cessation but also in the maintenance of abstinence.

\section{ACKNOWLEDGEMENTS}

The skilled technical assistance of Stéphanie Hamon and Claudine Léonardon is gratefully acknowledged. We thank John Alexander for critically reading the manuscript. 


\section{REFERENCES}

Alderson HL, Robbins TW, Everitt BJ (2000). Heroin selfadministration under a second-order schedule of reinforcement: acquisition and maintenance of heroin-seeking behavior in rats. Psychopharmacology 153: 120-133.

Arnone M, Maruani J, Chaperon F, Thiebot MH, Poncelet M, Soubrie $P$ et al (1997). Selective inhibition of sucrose and ethanol intake by SR 141716, an antagonist of central cannabinoid (CB1) receptors. Psychopharmacology 132: 104-106.

Arroyo M, Markou A, Robbins TW, Everitt BJ (1998). Acquisition, maintenance and reinstatement of intravenous cocaine selfadministration under a second-order schedule of reinforcement in rats: effects of conditioned cues and continuous access to cocaine. Psychopharmacology 140: 331-344.

Bevins RA, Besheer J, Pickett KS (2001). Nicotine-conditioned locomotor activity in rats: dopaminergic and GABAergic influences on conditioned expression. Pharmacol Biochem Behav 68: 135-145.

Brody AL, Mandelkern MA, London ED, Childress AR, Lee GS, Bota RG et al (2002). Brain metabolic changes during cigarette craving. Arch Gen Psychiatry 52: 1162-1172.

Caggiula AR, Donny EC, White AR, Chaudhri N, Booth S, Gharib MA et al (2001). Cue dependency of nicotine self-administration and smoking. Pharmacol Biochem Behav 70: 515-530.

Caggiula AR, Donny EC, White AR, Chaudhri N, Booth S, Gharib MA et al (2002). Environmental stimuli promote the acquisition of nicotine self-administration in rats. Psychopharmacology 163: 230-237.

Chaperon F, Soubrie P, Puech AJ, Thiebot MH (1998). Involvement of central cannabinoid (CB1) receptors in the establishment of place conditioning in rats. Psychopharmacology 135: 324-332.

Childress AR, Mozley PD, McElgin W, Fitzgerald J, Reivich M, O'Brien CP (1999). Limbic activation during cue-induced cocaine craving. Am J Psychiatry 156: 11-18.

Ciccocioppo R, Sanna PP, Weiss F (2001). Cocaine-predictive stimulus induces drug-seeking behavior and neural activation in limbic brain regions after multiple months of abstinence: reversal by D1 antagonists. Proc Natl Acad Sci USA 98: 1976-1981.

Cohen C, Bergis OE, Galli F, Lochead AW, Jegham S, Biton B et al (2003). SSR591813, (5aS,8S,10aR)-5a,6,9,10-tetrahydro,7H,11H8,10 a-methanopyrido[ $\left.2^{\prime}, 3^{\prime}: 5,6\right]$ pyrano[2,3-d]azepine, a novel selective and partial $\alpha_{4} \beta_{2}$ nicotinic receptor agonist with potential as an aid to smoking cessation. J Pharmacol Exp Ther 306: 407-420.

Cohen C, Perrault G, Voltz C, Steinberg R, Soubrié P (2002). SR141716, a central cannabinoid (CB1) receptor antagonist, blocks the motivational and dopamine-releasing effects of nicotine. Behav Pharmacol 13: 451-463.

Covey LS, Sullivan MA, Johnston JA, Glassman AH, Robinson MD, Adams DP (2000). Advances in non-nicotine pharmacotherapy for smoking cessation. Drugs 59: 17-30.

De Vries TJ, Homberg JR, Binnekade R, Raaso H, Schoeffelmeer ANM (2003). Cannabinoid modulation of the reinforcing and motivational properties of heroin and heroin-associated cues in rats. Psychopharmacology 168: 164-169.

De Vries TJ, Shaham Y, Homberg JR, Crombag H, Schuurman K, Dieben J et al (2001). A cannabinoid mechanism in relapse to cocaine seeking. Nature 7: 1151-1154.

Deminiere JM, Piazza PV, Le Moal M, Simon H (1989). Experimental approach to individual vulnerability to psychostimulant addiction. Neurosci Biobehav Rev 13: 141-147.

Everitt BJ, Dickinson A, Robbins TW (2001). The neuropsychological basis of addictive behavior. Brain Res Rev 36: $129-138$.

Everitt BJ, Robbins TW (2000). Second-order schedules of drug reinforcement in rats and monkeys: measurement of reinforcing efficacy and drug-seeking behavior. Psychopharmacology 153: 17-30.

Fattore L, Martellotta MC, Cossu G, Mascia MS, Fratta W (1999). CB1 cannabinoid receptor agonist WIN 55,212-2 decreases intravenous cocaine self-administration in rats. Behav Brain Res 104: 141-146.

Gerdeman GL, Partridge JG, Lupica CR, Lovinger DM (2003). It could be habit forming: drugs of abuse and striatal synaptic plasticity. Trends Neurosci 26: 184-192.

Goldberg SR, Spealman RD, Goldberg DM (1981). Persistent behavior at high rates maintained by intravenous self-administration of nicotine. Science 214: 573-575.

Grimm JW, Hope BT, Wise RA, Shaham Y (2001). Neuroadaptation. Incubation of cocaine craving after withdrawal. Nature 412: 141-142.

Ito R, Dalley JW, Howes SR, Robbins TW, Everitt BJ (2000). Dissociation in conditioned dopamine release in the nucleus accumbens core and shell in response to cocaine cues and during cocaine-seeking behavior in rats. J Neurosci 20: 7489-7495.

Ito R, Dalley JW, Robbins TW, Everitt BJ (2002). Dopamine release in the dorsal striatum during cocaine-seeking behavior under the control of a drug-associated cue. J Neurosci 15: $6247-6253$

Liu X, Weiss F (2002). Reversal of ethanol-seeking behavior by $\mathrm{D} 1$ and $\mathrm{D} 2$ antagonists in an animal model of relapse: differences in antagonist potency in previously ethanoldependent versus nondependent rats. J Pharmacol Exp Ther 300: 882-889.

Mailleux P, Vanderhaeghen JJ (1992). Distribution of neuronal cannabinoid receptor in the adult rat brain: a comparative receptor binding radioautography and in situ hybridization histochemistry. Neurosci 48: 655-668.

Markou A, Weiss F, Gold LH, Caine SB, Schulteis G, Koob GF (1993). Animal models of drug craving. Psychopharmacology 112: $163-182$.

McLaughlin J, See RE (2003). Selective inactivation of the dorsomedial prefrontal cortex and the basolateral amygdala attenuates conditioned-cued reinstatement of extinguished cocaine-seeking behavior in rats. Psychopharmacology 168: $57-65$.

Navarro M, Carrera MR, Fratta W, Valverde O, Cossu G, Fattore L et al (2001). Functional interaction between opioid and cannabinoid receptors in drug self-administration. J Neurosci 21: $5344-5350$.

O'Neill MF, Dourish CT, Iversen SD (1991). Evidence for an involvement of D1 and D2 dopamine receptors in mediating nicotine-induced hyperactivity in rats. Psychopharmacology 104: 343-350.

Olausson P, Jentsch JD, Taylor JR (2003). Repeated nicotine exposure enhances reward-related learning in the rat. Neuropsychopharmacology 28: 1264-1271.

Phillips PEM, Stuber GD, Heien MLAV, Wightman RM, Carelli RM (2003). Subsecond dopamine release promotes cocaine seeking. Nature 422: 614-618.

Piazza PV, Deminiere JM, Le Moal M, Simon H (1989). Factors that predict individual vulnerability to amphetamine self-administration. Science 245: 1511-1513.

Pilla M, Perachon S, Sautel F, Garrido F, Mann A, Wermuth CG et al (1999). Selective inhibition of cocaine-seeking behavior by a partial dopamine D3 receptor agonist. Nature 400: 371-375.

Pistis M, Perra S, Pillolla G, Melis M, Gessa GL, Muntoni AL (2002). Cannabinoids modulate neuronal firing in the rat basolateral amygdala: evidence for CB1- and non-CB1-mediated actions. Neuropharmacology 46: 115-125.

Rezvani AH, Levin ED (2001). Cognitive effects of nicotine. Biol Psychiatry 49: 258-267.

Rinaldi-Carmona M, Barth F, Heaulme M, Shire D, Calandra B, Congy C et al (1994). SR141716A, a potent and selective 
antagonist of the brain cannabinoid receptor. FEBS Lett 350: 240-244.

Schindler CW, Panlilio LV, Goldberg SR (2002). Second-order schedules of drug self-administration in animals. Psychopharmacology 163: 327-344.

Schroeder BE, Binzak JM, Kelley AE (2001). A common profile of prefrontal cortical activation following exposure to nicotineor chocolate-associated contextual cues. Neuroscience 105: 535-545.

See RE, Kruzich PJ, Grimm JW (2001). Dopamine, but not glutamate, receptor blockade in the basolateral amygdala attenuates conditioned reward in a rat model of relapse to cocaine-seeking behavior. Psychopharmacology 154: 301-310.

Shaham Y, Shalev U, Lu L, De Wit H, Stewart J (2003). The reinstatement model of drug relapse: history, methodology and major findings. Psychopharmacology 168: 3-20.

Shalev U, Morales M, Hope B, Yap J, Shaham Y (2001). Timedependent changes in extinction behavior and stress-induced reinstatement of drug seeking following withdrawal from heroin in rats. Psychopharmacology 156: 98-107.

Silagy C, Mant D, Fowler G, Lodge M (1994). Meta-analysis on efficacy of nicotine replacement therapies in smoking cessation. Lancet 243: 139-142.
Sinha R, Fise T, Aubin LR, O’Malley SS (2000). Psychological stress, drug-related cues and cocaine craving. Psychopharmacology 152: 140-148.

Suto N, Austin JD, Vezina P (2001). Locomotor response to novelty predicts a rat's propensity to self-administer nicotine. Psychopharmacology 158: 175-180.

Vinklerova J, Nováková J, Sulcová A (2002). Inhibition of methamphetamine self-administration in rats by cannabinoid receptor antagonist AM 251. J Psychopharmacol 16: 139-143.

Vorel SR, Ashby Jr CR, Paul M, Liu X, Hayes R, Hagan JJ et al (2002). Dopamine D3 receptor antagonism inhibits cocaineseeking and cocaine-enhanced brain reward in rats. J Neurosci 22: 9595-9603.

Weiss F, Ciccocioppo R, Parsons LH, Katner S, Liu X, Zorrilla EP et al (2001). Compulsive drug-seeking behavior and relapse. Neuroadaptation, stress, and conditioning factors. Ann NY Acad Sci 937: 1-26.

Weiss F, Maldonado-Vlaar CS, Parsons LH, Kerr TM, Smith DL, Ben-Shahar O (2000). Control of cocaine-seeking behavior by drug-associated stimuli in rats: effects on recovery of extinguished operant-responding and extracellular dopamine levels in amygdala and nucleus accumbens. Proc Natl Acad Sci USA 97: 4321-4326. 